\title{
FIBRINOLYSIS IN MYOCARDIAL INFARCTION
}

\author{
BY \\ ROBERT HUME \\ From The University Department of Medicine, Royal Infirmary, Glasgow
}

Received March 29, 1957

Fibrinolysis is the process of fibrin digestion by an enzyme system present in the blood. Although fibrinolytic activity has been found in the normal, and in many pathological states, its rôle remains obscure. It seems likely, however, that such a process may take part in the normal hæmostatic equilibrium of the body and may be operative in the processes of resolution and healing (Astrup, 1956).

This paper records serial observations with respect to this fibrinolytic activity in cases of myocardial infarction.

\section{MATERIALS AND MethodS}

Preparation of reagents. 3.8 per cent sodium citrate and $\mathrm{M} / 40$ calcium chloride were prepared as described by Biggs and Macfarlane (1953).

Thrombin was prepared by the method of Biggs and Macfarlane (1953) from plasma obtained from expired bank blood. The thrombin was divided into $2 \mathrm{ml}$. lots and stored at $-20^{\circ} \mathrm{C}$. Fresh samples were used each day and diluted with normal saline so that the clotting time of $0.2 \mathrm{ml}$. plasma and $0 \cdot 2 \mathrm{ml}$. thrombin was 15 seconds.

Buffer. To $5.0 \mathrm{ml}$. of stock solution of sodium acetate/sodium veronal $(9.714 \mathrm{~g}$. of Na.OAc $3 \mathrm{H}_{2} \mathrm{O}$ and $14.714 \mathrm{~g}$. Na. veronal made up to $500 \mathrm{ml}$. in $\mathrm{CO}_{2}$ free water) was added $5.0 \mathrm{ml}$. of $0 \cdot 1$ per cent hydrochloric acid and $15 \mathrm{ml}$. distilled water $(p \mathrm{H} 7 \cdot 4$ measured by $p \mathrm{H}$ meter $)$. Fresh buffer was made on alternate days from stock solution.

Glassware. $\frac{1}{2} \times 3$-inch tubes were used throughout. The tubes were washed with a solution of deosan detergent, thoroughly rinsed and dried overnight in an oven at $100^{\circ} \mathrm{C}$.

Collection of specimens. Blood was collected by clean venepuncture through a wide-bore needle (S.W.G. 18), care being taken to avoid frothing; $9 \mathrm{ml}$. of blood was delivered into an ice-cold $10 \mathrm{ml}$. graduated centrifuge tube containing $1 \mathrm{ml}$. of sodium citrate. The centrifuge tubes were surrounded with ice in a glass container for transport to the laboratory. The specimens were collected between 9 and 10 a.m. and centrifuged at $4^{\circ} \mathrm{C}$. for 3-5 minutes at 6000 r.p.m. in a refrigerated centrifuge using a high-speed attachment. The interval between collecting the blood and starting the estimation of the fibrinolytic activity varied between $\frac{1}{2}-1$ hour.

Measurement of fibrinolytic activity. A modified dilution technique was employed (Macfarlane and Biggs, 1946). Two sets of five tubes were prepared as follows: $\frac{1}{2} \mathrm{ml}$. of normal saline was added to each tube in a water bath at $37^{\circ} \mathrm{C} .: \frac{1}{2} \mathrm{ml}$. of plasma was added to the first tube and doubling dilutions made, giving dilutions of $1: 2,1: 4,1: 8,1: 16,1: 32$. The $1: 2$ dilution was not used in the test. One row of tubes was immediately clotted by the addition of $\frac{1}{2} \mathrm{ml}$. of thrombin solution to each tube and the other row was clotted by the addition of $\frac{1}{2} \mathrm{ml}$. of calcium chloride solution to each tube. The lysis time was estimated from the addition of calcium and thrombin. One hour after the addition of thrombin and calcium $\frac{1}{2} \mathrm{ml}$. of buffer was added to each tube. The tubes were gently agitated in order to free the clot from the sides. The total amount in each tube was 
$1.5 \mathrm{ml}$. Fearnley and Lackner (1955) have shown that fibrinolysin is not diluted by the addition of buffer after clotting has occurred.

Readings. The tubes were inspected at 6 hours and 24 hours. The number of tubes in which complete lysis had occurred, that is in which the clot had completely disappeared or disintegrated, was counted. The number of tubes lysed at 6 hours was added to the number found lysed at 24 hours. As there were two rows of four tubes the highest possible number lysed on any one inspection was eight. The maximum activity recordable by this means was therefore sixteen. It was hoped in this way to make more apparent the difference between rapid lysis and lysis that took 24 hours to complete.

Patients. Ten patients (seven men and three women) diagnosed clinically and confirmed by electrocardiography as having myocardial infarction (nine showing well-marked $\mathrm{Q}$ wave changes and the tenth irrefutable sequential changes) were examined daily for fibrinolytic activity for

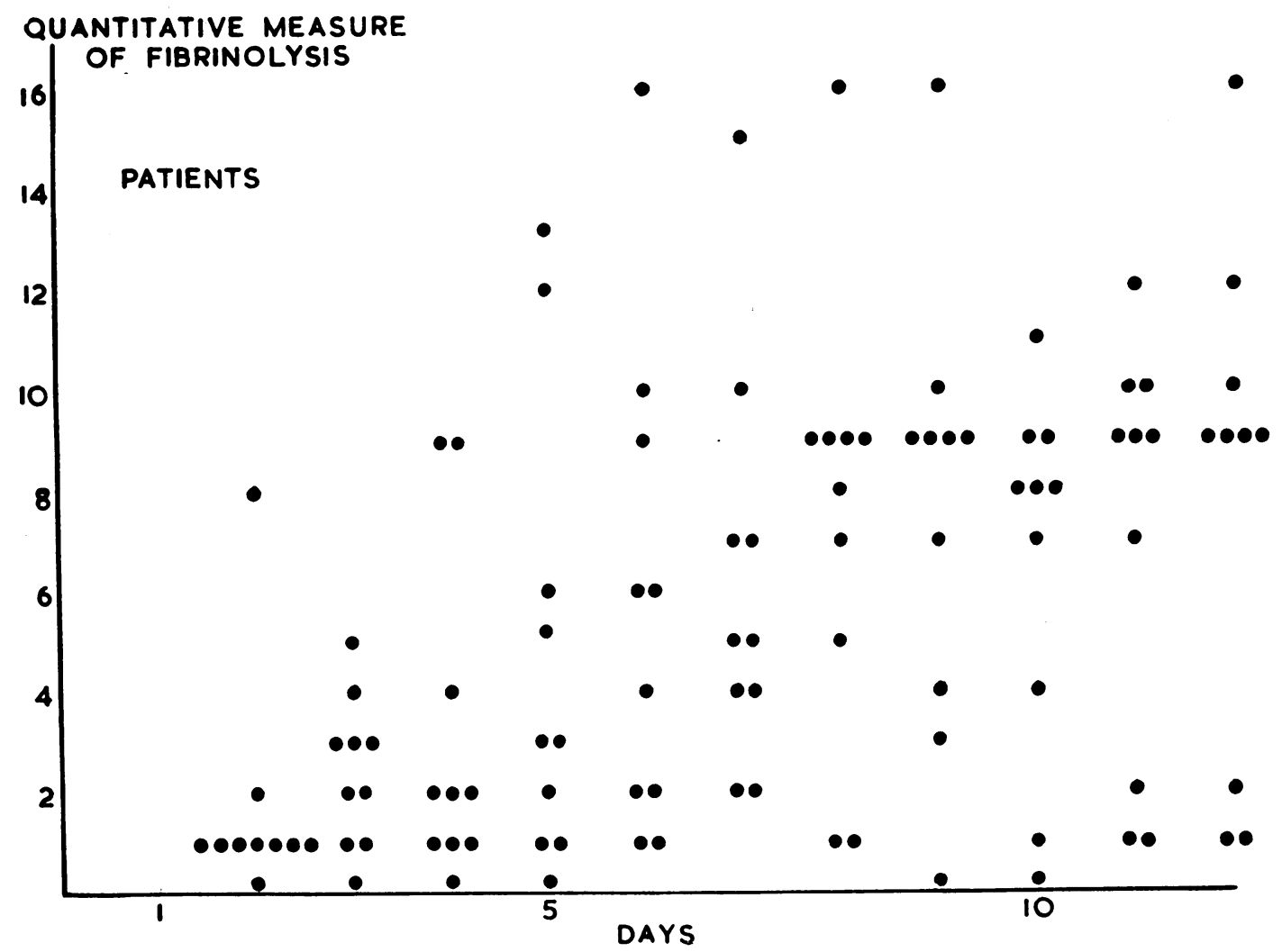

FIG. 1.-The individual daily readings of the ten patients with myocardial infarction are plotted for the first twelve days.

twenty-eight days. The first estimation was made on the day following the episode. On admission each patient received a single injection of 40,000 I.U. of heparin in a modified Pitkin's menstruum (Boots) intramuscularly and $200 \mathrm{mg}$. of phenylindanedione orally. The phenylindanedione was continued throughout the period of observation, the dose being regulated by daily estimations of the one-stage clotting time.

Controls. Ten patients (five men and five women) who had been admitted to the mental observation wards in the Eastern District Hospital, Glasgow, were used as controls, and followed for a similar period. 
Effect of heparin. Observations were made on three of the controls who were given a single injection of 40,000 I.U. of heparin in a modified Pitkin's menstruum intramuscularly.

Effect of phenylindanedione. One patient who was admitted with severe chest pain and subsequently showed no evidence of myocardial infarction was given phenylindanedione alone, by mouth over a period of eight days, and observations made.

Effect of shock. Ten patients admitted to the surgical wards as acute emergencies were examined for fibrinolytic activity the day following admission. These patients were suffering from a variety of conditions varying from fractured limbs and crush injuries to abdominal emergencies.

\section{RESULTS}

The individual results for the first twelve days of the ten patients with myocardial infarction are plotted in Fig. 1. The individual results of the ten controls for the first twelve days are plotted in Fig. 2. The mean daily readings are shown graphically for the twenty-eight days in Fig. 3, in

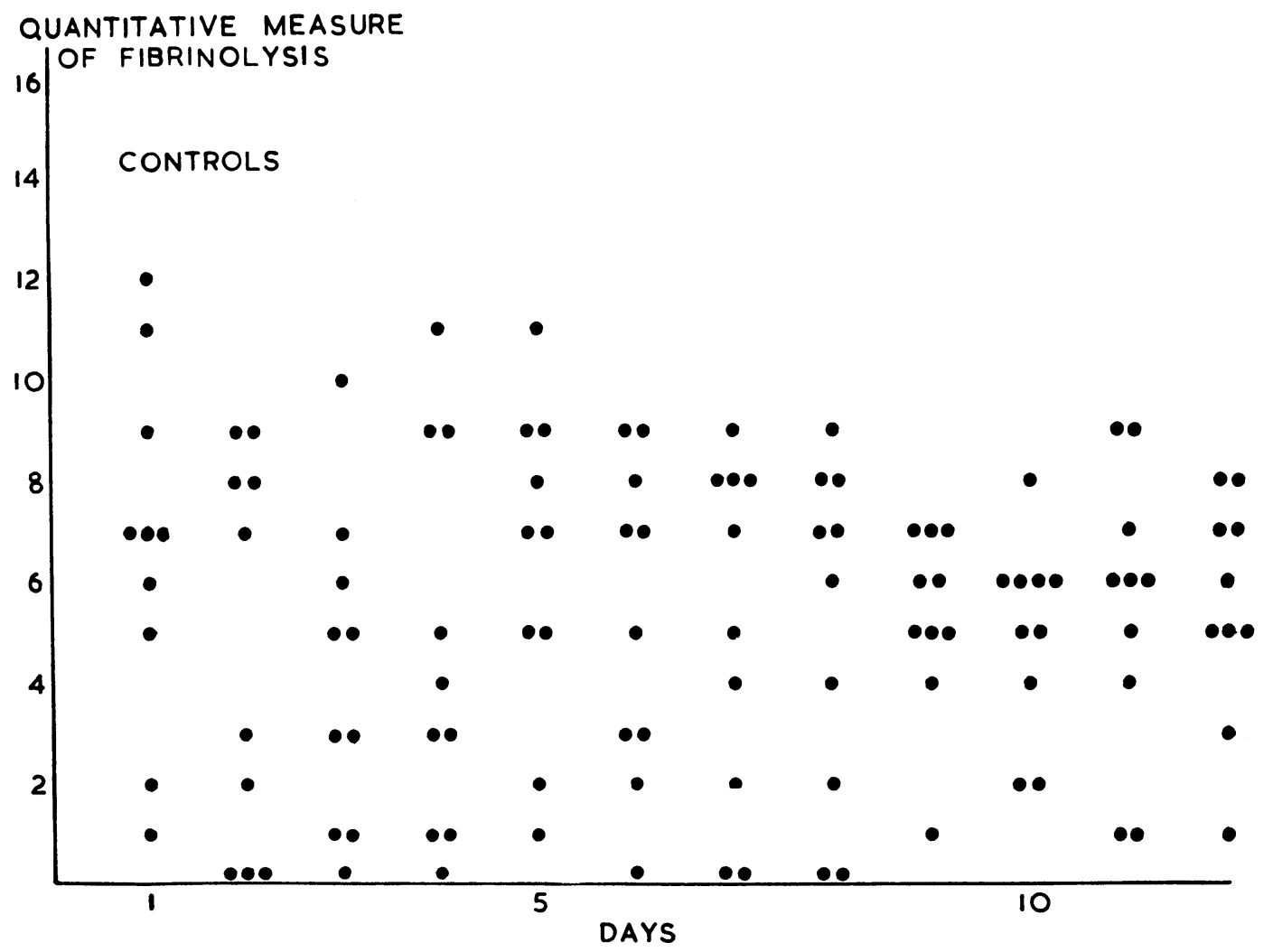

FIG. 2.-The individual daily readings of the ten controls are plotted for the first twelve days.

which those of the patients are contrasted with those of the controls. Analysis of variance showed that for the ten controls there was no significant day-to-day variation $(F=1.03, P>0.05)$. The patients with myocardial infarction showed, however, a significant day-to-day variation $(F=3.49$, $\mathrm{P}<0 \cdot 01)$. The day-to-day variation from the ninth to the twenty-eighth day after the episode was considered and no significant variation was found $(\mathrm{F}=1 \cdot 36, \mathrm{P}>0.05)$ but the second to the eighth days showed a significant day-to-day variation $(\mathrm{F}=6.60, \mathrm{P}<0 \cdot 01)$. Fig. 3 shows that the fibrinolytic activity increases uniformly with time over the first eight days. It would appear, therefore, that following myocardial infarction there was a depression of fibrinolytic activity which only reverted to normal levels after eight days. 


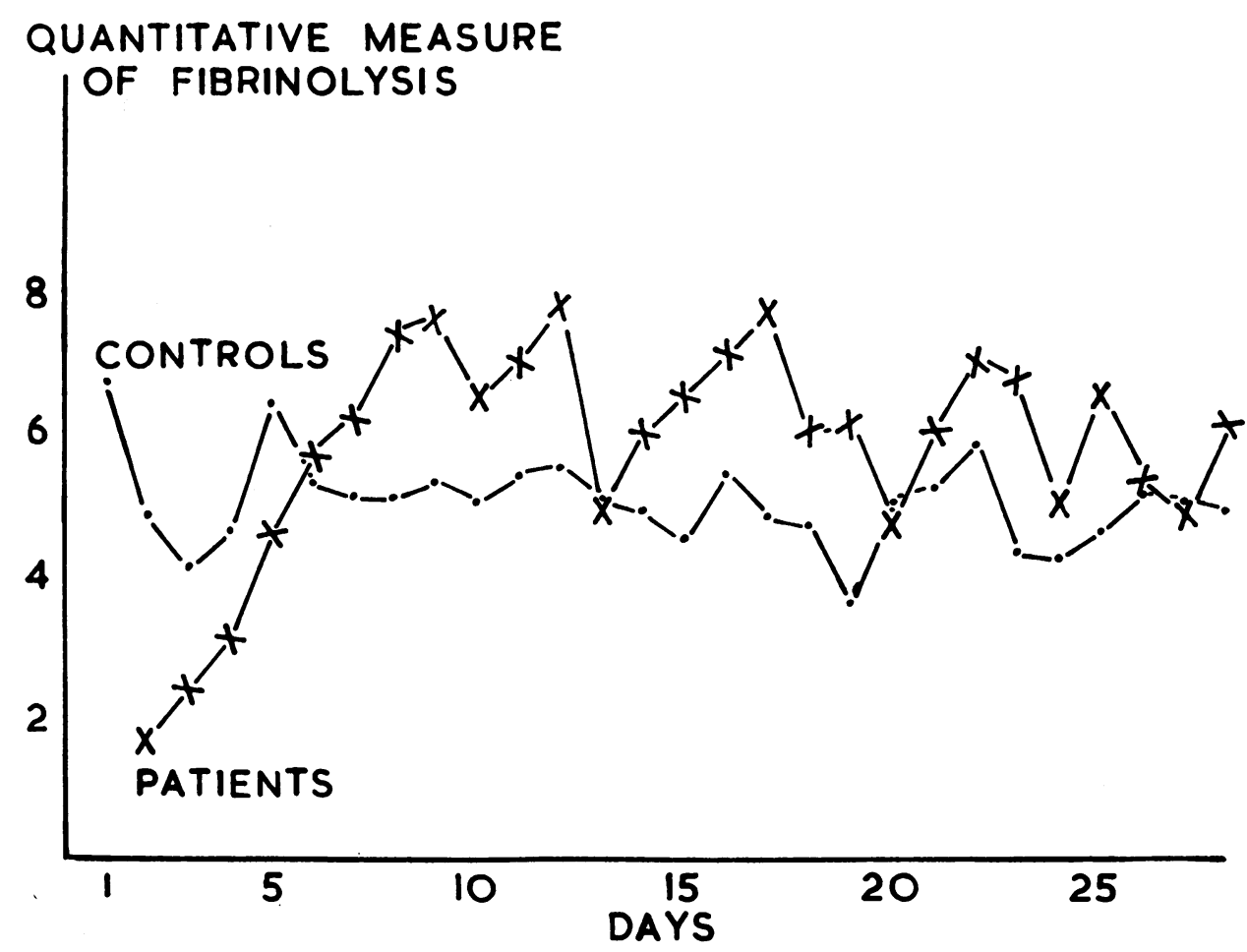

Fig. 3.-The mean daily readings of the ten patients with myocardial infarction and the ten controls are contrasted. The fibrinolytic activity of the patients with infarction increases uniformly with time over the first eight days. There is no statistically-significant day-to-day variation in the controls.

It seemed important, however, to eliminate three possibilities as having given rise to this phenomenon. First, was the initial injection of heparin responsible for the depression of fibrinolytic activity? Heparin has been reported to inhibit fibrinolysis in in vitro study (Astrup and Alkjaersig, 1952) and it has been suggested that it potentiates its action if given intravenously (Greig, 1956). Three of the controls were therefore given 40,000 I.U. of heparin in a modified Pitkin's menstruum intramuscularly and observed over the next fourteen days. The results were unlike those produced by the coronary patients and were compatible with normal fluctuation in activity.

It did not seem likely that the phenylindanedione was responsible as this drug had been continued throughout the period of observation after normal levels of fibrinolytic activity had been obtained. However, one patient who was admitted with severe chest pain and subsequently showed no evidence of myocardial infarction was given phenylindanedione alone by mouth, and observed over eight days. There was no depression in fibrinolytic activity and the result was of interest, too, in that it was in keeping with the negative laboratory findings of myocardial infarction.

The third possibility that was examined was whether the reaction was a non-specific one to some severe physically disturbing incident. The mean of the results made on the ten surgical patients is shown by histogram in Fig. 4 labelled "surgical." This is compared on the same diagram with the mean reading of the first day results made on the coronary patients, with the mean daily reading of the controls and with the mean reading of eighty sporadic observations made on eighty different patients, excluding patients with myocardial infarction and liver disease. The scatter of results is similar to that of the controls and the mean reading is not significantly different although significantly different from the coronary patients. It would appear, therefore, that the reaction is not a non-specific one to "shock," the word shock being used in its broadest sense as the patients with myocardial infarction were in fact not all clinically shocked. 


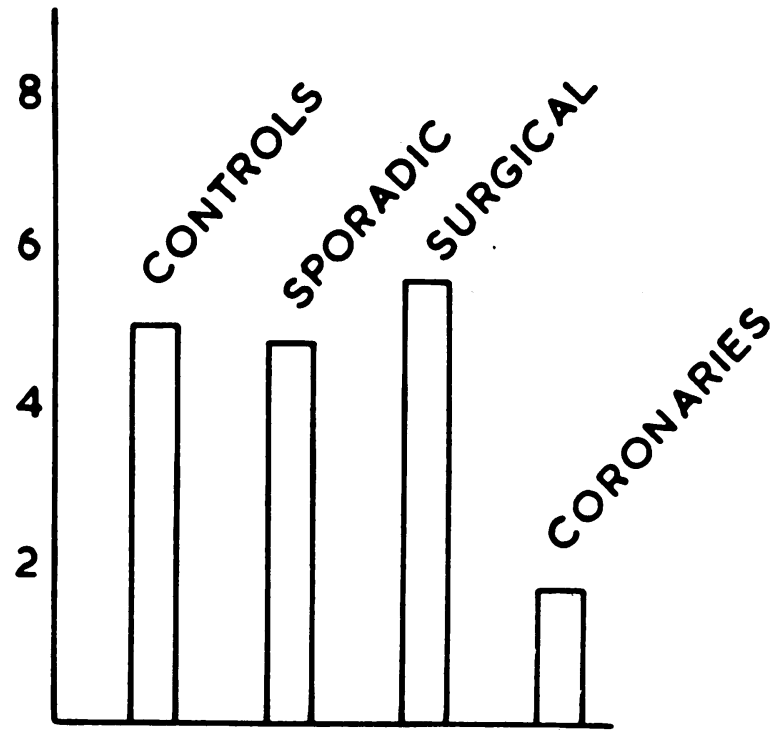

FIG. 4.-Quantitative measure of fibrinolysis. The mean reading of the ten " shocked" patients labelled " surgical" is compared with the mean reading of the first-day results made on the patients with myocardial infarction, with the mean daily reading of the controls and with the mean reading of eighty sporadic observations made on eighty different patients.

\section{Discussion}

The ætiology of myocardial infarction is uncertain. It is not known whether the cause lies in the wall of the coronary artery or in the contained blood. Duguid $(1954,1955)$ has presented evidence to show that mural thrombi may form and lead to atheromatous plaque formation. Others have claimed that following myocardial infarction there may be an alteration in blood coagulation (Hines and Kessler, 1945; Ogura et al., 1946; Peel, 1953, 1956). Fibrin formation in the coronary vessel is, therefore, of importance in this condition whether in the ætiology of atheroma or in the formation of the thrombus.

In the formation of fibrin, there is a balance of activators and inhibitors. Similarly in the removal of fibrin by fibrinolysis there is probably a balance of activators and inhibitors. As distinct from the system leading to the formation of fibrin, the system capable of removing fibrin may be of equal importance in this condition.

The systems for the formation and the removal of fibrin may be intimately related, as it has been shown that dietary fats can accelerate coagulation in vitro (MacLagan and Billimoria, 1956; O'Brien, 1956; Barkham et al., 1956) and possibly inhibit fibrinolysis (Greig, 1956).

It is not possible, at present, to put a final interpretation on the phenomenon described. It does not appear likely from the evidence presented that the depression of fibrinolytic activity following myocardial infarction was due either to the initial injection of heparin or to phenylindanedione, nor was it a non-specific reaction to some severe physically disturbing incident as evinced by the observations on the surgical patients. It could possibly, however, represent a change in the blood that has favoured the occurrence of myocardial infarction, but the fact that the changes generally last for eight days would then be unlikely.

\section{SUMMARY}

This paper reports the results of measurement of fibrinolytic activity in patients following myocardial infarction. The fibrinolytic activity was studied in ten patients for twenty-eight days subsequent to the episode and compared with ten controls. In the patients with myocardial 
infarction there was depression of fibrinolytic activity and this did not reach normal levels until after eight days. It did not appear that the treatment received by the patients was responsible for this phenomenon, nor was it a non-specific reaction to some severe physically disturbing incident.

I wish to thank Professor L. J. Davis for his helpful advice and criticism in the preparation of this paper and also Professor W. A. Mackey, Mr. C. J. Longland, and Dr. I. M. Sclare for permission to investigate their patients. I am also grateful to Dr. R. A. Robb for the statistical analysis of the results, to Dr. A. S. Douglas for his interest in this work, and to the Advisory Committee on Medical Research for Scotland for defraying part of the cost of the equipment. Most of this work was done during the tenure of the Hutchison Research Scholarship.

\section{REFERENCES}

Astrup, T., and Alkjaersig, N. (1952). Nature, London, 169, 314.

(1956). Blood, 11, 781.

Barkham, P., Newlands, M. J., and Wild, F. (1956). Lancet, $2,234$.

Biggs, R., and Macfarlane, R. G. (1953). Human Blood Coagulation and Its Disorders. Blackwell, Scientific Publications. Oxford.

Duguid, J. B. (1954). Lancet, 1, 891.

(1955). Brit. med. Bull., 2, 36.

Fearnley, G. R., and Lackner, R. (1955). Brit. J. Hamat., 1, 189.

Greig, H. B. W. (1956). Lancet, 2, 16.

Hines, L. E., and Kessler, D. L. (1945). Arch. intern. Med., 75, 248.

Macfarlane, R. G., and Biggs, R. (1946). Lancet, 2, 862.

MacLagan, H. F., and Billimoria, J. D. (1956). Lancet, 5, 235.

O'Brien, J. R. (1956). Lancet, 5, 432.

Ogura, J. H., Fetter, N. R., Blankenhorn, M. A., and Glueck, H. I. (1946). J. clin. Invest., 25, 586.

Peel, A. A. F. (1953). Brit. Heart J., 15, 8.

(1956). Brit. Heart J., 18, 378. 